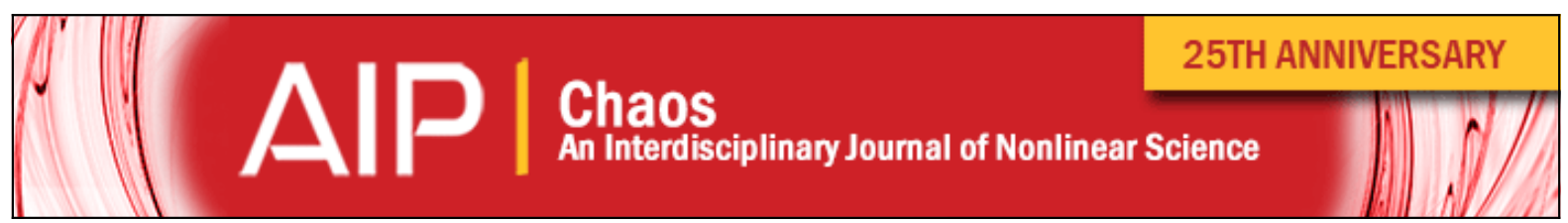

$\mathrm{pH}-$ oscillations in the bromate-sulfite reaction in semibatch and in gel-fed batch reactors

Eszter Poros, Krisztina Kurin-Csörgei, István Szalai, Gyula Rábai, and Miklós Orbán

Citation: Chaos 25, 064602 (2015); doi: 10.1063/1.4921176

View online: http://dx.doi.org/10.1063/1.4921176

View Table of Contents: http://scitation.aip.org/content/aip/journal/chaos/25/6?ver=pdfcov

Published by the AIP Publishing

Articles you may be interested in

Re-entrant phase diagram and $\mathrm{p} \mathrm{H}$ effects in cross-linked gelatin gels

J. Chem. Phys. 129, 134902 (2008); 10.1063/1.2985655

Pattern formation in the ferrocyanide-iodate-sulfite reaction: The control of space scale separation

Chaos 18, 026105 (2008); 10.1063/1.2912719

Categorization of rheological scaling models for particle gels applied to casein gels

J. Rheol. 46, 11 (2002); 10.1122/1.1423311

Multiple-phase behavior and its microscopic implication for 4-acrylamidosalicylic acid gel

J. Chem. Phys. 114, 6906 (2001); 10.1063/1.1357201

Static inhomogeneities and dynamics of swollen and reactor-batch polymer gels

J. Chem. Phys. 112, 442 (2000); 10.1063/1.480631

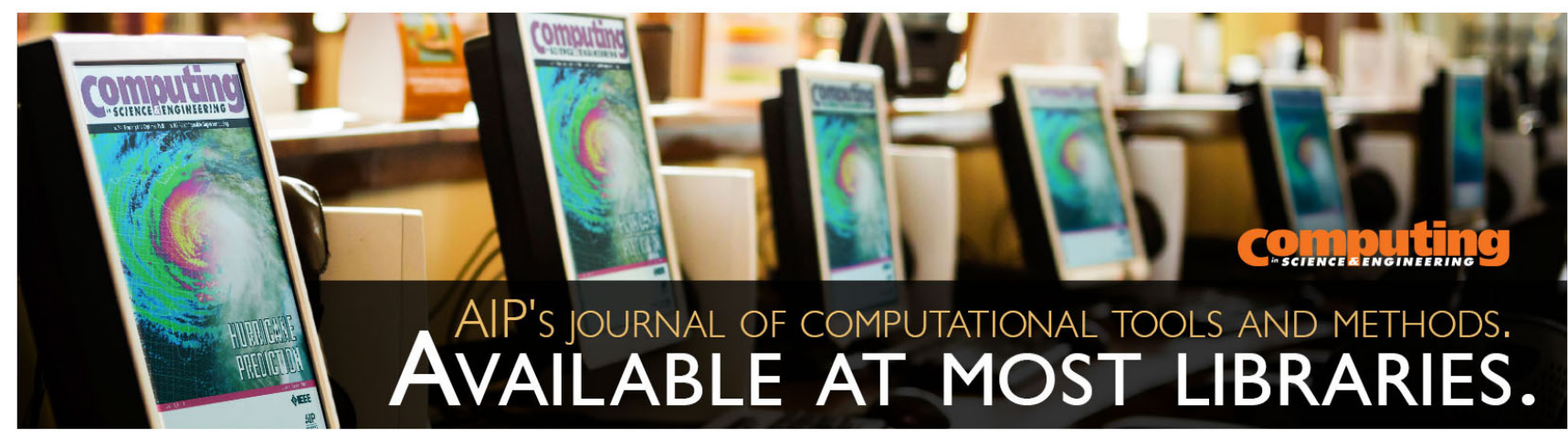




\title{
pH-oscillations in the bromate-sulfite reaction in semibatch and in gel-fed batch reactors
}

\author{
Eszter Poros, ${ }^{1}$ Krisztina Kurin-Csörgei, ${ }^{1}$ István Szalai, ${ }^{1}$ Gyula Rábai, ${ }^{2}$ and Miklós Orbán ${ }^{1, a)}$ \\ ${ }^{1}$ Department of Analytical Chemistry, Institute of Chemistry, L. Eötvös University, P.O. Box 32, \\ H-1518 Budapest 112, Hungary \\ ${ }^{2}$ Institute of Physical Chemistry, University of Debrecen, P.O. Box 7, H-4010 Debrecen, Hungary
}

(Received 26 February 2015; accepted 22 April 2015; published online 20 May 2015)

\begin{abstract}
The simplest bromate oxidation based $\mathrm{pH}$-oscillator, the two component $\mathrm{BrO}_{3}{ }^{-}-\mathrm{SO}_{3}{ }^{2-}$ flow system was transformed to operate under semibatch and closed arrangements. The experimental preconditions of the $\mathrm{pH}$-oscillations in semibatch configuration were predicted by model calculations. Using this information as guideline large amplitude $(\Delta \mathrm{pH} \sim 3)$, long lasting (11-24 $\mathrm{h})$ $\mathrm{pH}$-oscillations accompanied with only a $20 \%$ increase of the volume in the reactor were measured when a mixture of $\mathrm{Na}_{2} \mathrm{SO}_{3}$ and $\mathrm{H}_{2} \mathrm{SO}_{4}$ was pumped into the solution of $\mathrm{BrO}_{3}{ }^{-}$with a very low rate. Batch-like $\mathrm{pH}$-oscillations, similar in amplitude and period time appeared when the sulfite supply was substituted by its dissolution from a gel layer prepared previously in the reactor in presence of high concentration of $\mathrm{Na}_{2} \mathrm{SO}_{3}$. The dissolution $v s$ time curve and the $\mathrm{pH}$-oscillations in the semibatch and closed systems were successfully simulated. Due to the simplicity in composition and in experimental technique, the semibatch and batch-like $\mathrm{BrO}_{3}{ }^{-}-\mathrm{SO}_{3}{ }^{2-} \mathrm{pH}$-oscillators may become superior to their CSTR (continuous flow stirred tank reactor) version in some present and future applications. (C) 2015 AIP Publishing LLC.

[http://dx.doi.org/10.1063/1.4921176]
\end{abstract}

All pH-oscillators known so far have been discovered in continuous flow stirred tank reactor. There is an increasing interest in developing batch and semibatch pHoscillators, because in some suggested applications of the pH-oscillators, the use of flow reactor arrangement is not feasible. With our recently proposed method, we were successful with converting the bromate-sulfite-ferrocyanide and the bromate-sulfite-manganese(II) two-substrate pHoscillators to function under both semibatch and closed conditions. In this work, we report on transforming the simplest bromate-based pH-oscillator, the bromate-sulfite core system to the form that operates in closed and halfclosed versions. In the semibatch system, the high amplitude pH-oscillations can be maintained for $24 \mathrm{~h}$. In the batch-like system, the number of oscillations is less but due to the high amplitude and long period time, this one may also be capable of inducing periodic changes not only in the fast chemical equilibria but in the much slower $\mathrm{pH}$ governed physical processes or properties as well, for example, in shrinking and swelling of hydrogels or in the permeability of a membrane. These responses may constitute the basis of some applications of pH-oscillators. The use of closed, even half-closed pH-oscillators instead of their flow equivalents would surely facilitate the fabrication of utilizable devices, such as molecular motor or pulsating drug delivery system.

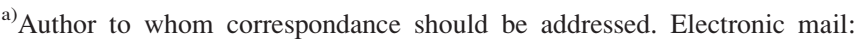
orbanm@chem.elte.hu.
}

\section{INTRODUCTION}

The autocatalytic oxidation of a mixture of the sulfitehydrogensulfite by bromate ions in an unbuffered aqueous solution has long been used as an important composite reaction in the systematically designed $\mathrm{pH}$-oscillatory systems. In order to obtain pH-oscillations in a continuous flow stirred tank reactor (CSTR), this hydrogen ion producing autocatalytic reaction should be coupled to a hydrogen ion consuming reaction. A newly recognised possibility of $\mathrm{H}^{+}$consumption in the bromate-sulfite based oscillatory reactions is the partial oxidation of the sulfite by bromate. The sulfur(IV) species (sulfurous acid, aqueous sulfur dioxide, and hydrogen sulfite ion) can be oxidized not only to sulfate ion but also to dithionate ion. The main product of the bromate oxidation of sulfur(IV) is, of course, sulfur(VI) $\left(\mathrm{SO}_{4}{ }^{2-}\right)$ but some small part $(1-2 \%)$ is oxidized simultaneously to sulfur( $\mathrm{V})\left(\mathrm{S}_{2} \mathrm{O}_{6}{ }^{2-}\right)$ as reported by Higginson and Marshall. ${ }^{1}$ Formation of $\mathrm{S}_{2} \mathrm{O}_{6}{ }^{2-}$ is accompanied with consumption of $\mathrm{H}^{+}$(reaction 1, 2 and 5 in Table I), therefore this reaction path can serve as $\mathrm{H}^{+}$consuming negative feedback channel. Based on this recognition, $\mathrm{pH}$ oscillations have recently been produced experimentally in the bromate-sulfite CSTR reaction without coupling it to any additional $\mathrm{H}^{+}$consuming reaction. ${ }^{2}$ The twocomponent $\mathrm{BrO}_{3}{ }^{-}-\mathrm{SO}_{3}{ }^{2-} \mathrm{CSTR}$ reaction shows oscillations only in a relatively narrow range of the experimental parameters (input concentrations, flow rate, and temperature), but the ranges become significantly wider if the $\mathrm{BrO}_{3}{ }^{-}-\mathrm{SO}_{3}{ }^{2-}$ reaction is coupled to other $\mathrm{H}^{+}$consuming processes like to the reactions that take place between bromate and ferrocyanide, ${ }^{3}$ hydrogen ion and marble, ${ }^{4}$ bromate and manganese(II), ${ }^{5}$ hydrogen ion and hydrogen 
TABLE I. The composite reactions, empirical rate laws, and the rate constant values used in the model calculations.

\begin{tabular}{|c|c|c|c|}
\hline No. & Reactions & & Rate laws \\
\hline 1. & $\mathrm{SO}_{3}^{2-}+\mathrm{H}^{+} \leftrightarrow \mathrm{HSO}_{3}^{-}$ & & $\mathrm{r}_{1}=\mathrm{k}_{1}\left[\mathrm{SO}_{3}^{2-}\right]\left[\mathrm{H}^{+}\right] ; \mathrm{r}_{-1}=\mathrm{k}_{-1}\left[\mathrm{HSO}_{3}^{-}\right]$ \\
\hline 2. & $\mathrm{HSO}_{3}^{-}+\mathrm{H}^{+} \leftrightarrow \mathrm{H}_{2} \mathrm{SO}_{3}$ & & $\mathrm{r}_{2}=\mathrm{k}_{2}\left[\mathrm{HSO}_{3}^{-}\right]\left[\mathrm{H}^{+}\right] ; \mathrm{r}_{-2}=\mathrm{k}_{-2}\left[\mathrm{H}_{2} \mathrm{SO}_{3}^{-}\right]$ \\
\hline 3. & $3 \mathrm{HSO}_{3}^{-}+\mathrm{BrO}_{3}^{-} \rightarrow 3 \mathrm{SO}_{4}{ }^{2-}+\mathrm{Br}^{-}+3 \mathrm{H}^{+}$ & & $\mathrm{r}_{3}=\mathrm{k}_{3}\left[\mathrm{HSO}_{3}^{-}\right]\left[\mathrm{BrO}_{3}^{-}\right]$ \\
\hline 4. & $3 \mathrm{H}_{2} \mathrm{SO}_{3}+\mathrm{BrO}_{3}^{-} \rightarrow 3 \mathrm{SO}_{4}^{2-}+\mathrm{Br}^{-}+6 \mathrm{H}^{+}$ & & $\mathrm{r}_{4}=\mathrm{k}_{4}\left[\mathrm{H}_{2} \mathrm{SO}_{3}\right]\left[\mathrm{BrO}_{3}^{-}\right]$ \\
\hline 5. & $6 \mathrm{H}_{2} \mathrm{SO}_{3}+\mathrm{BrO}_{3}^{-} \rightarrow 3 \mathrm{~S}_{2} \mathrm{O}_{6}^{2-}+\mathrm{Br}^{-}+3 \mathrm{H}_{2} \mathrm{O}+6 \mathrm{H}^{+}$ & & $\mathrm{r}_{5}=\mathrm{k}_{5}\left[\mathrm{H}_{2} \mathrm{SO}_{3}\right]\left[\mathrm{BrO}_{3}^{-}\right]$ \\
\hline \multicolumn{4}{|l|}{ Rate constants } \\
\hline \multicolumn{2}{|c|}{$\mathrm{T}=35^{\circ} \mathrm{C}$} & \multicolumn{2}{|r|}{$\mathrm{T}=45^{\circ} \mathrm{C}$} \\
\hline $\mathrm{k}_{1}: 1.0 \times 10^{10} \mathrm{M}^{-1} \mathrm{~s}^{-1}$ & $\mathrm{k}_{-1}: 1.0 \times 10^{3} \mathrm{~s}^{-1}$ & $\mathrm{k}_{1}: 2.0 \times 10^{10} \mathrm{M}^{-1} \mathrm{~s}^{-1}$ & $\mathrm{k}_{-1}: 2.0 \times 10^{3} \mathrm{~s}^{-1}$ \\
\hline $\mathrm{k}_{2}: 6.0 \times 10^{9} \mathrm{M}^{-1} \mathrm{~s}^{-1}$ & $\mathrm{k}_{-2}: 1.0 \times 10^{8} \mathrm{~s}^{-1}$ & $\mathrm{k}_{2}: 12.0 \times 10^{9} \mathrm{M}^{-1} \mathrm{~s}^{-1}$ & $\mathrm{k}_{-2}: 2.0 \times 10^{8} \mathrm{~s}^{-1}$ \\
\hline $\mathrm{k}_{3}: 0.0653 \mathrm{M}^{-1} \mathrm{~s}^{-1}$ & & $\mathrm{k}_{3}: 0.13 \mathrm{M}^{-1} \mathrm{~s}^{-1}$ & \\
\hline $\mathrm{k}_{4}: 18 \mathrm{M}^{-1} \mathrm{~s}^{-1}$ & & $\mathrm{k}_{4}: 30 \mathrm{M}^{-1} \mathrm{~s}^{-1}$ & \\
\hline $\mathrm{k}_{5}: 0.70 \mathrm{M}^{-1} \mathrm{~s}^{-1}$ & & $\mathrm{k}_{5:} 2.0 \mathrm{M}^{-1} \mathrm{~s}^{-1}$ & \\
\hline
\end{tabular}

carbonate. ${ }^{6}$ A simple reaction scheme, consisting of the protonation equilibria of $\mathrm{SO}_{3}{ }^{2-}$ and $\mathrm{HSO}_{3}{ }^{-}$(reactions 1 and 2 in Table I), the oxidation of $\mathrm{HSO}_{3}{ }^{-}$and $\mathrm{H}_{2} \mathrm{SO}_{3}$ by $\mathrm{BrO}_{3}{ }^{-}$ to $\mathrm{SO}_{4}{ }^{2-}$ (reactions 3 and 4), and the oxidation of $\mathrm{H}_{2} \mathrm{SO}_{3}$ to $\mathrm{S}_{2} \mathrm{O}_{6}{ }^{2-}$ has successfully been used to simulate the observed $\mathrm{pH}$-oscillations and other dynamical phenomena in the bromate-sulfite CSTR reaction. ${ }^{2}$

Recently, some practical applications of the $\mathrm{pH}$-oscillators have been proposed. For such applications, the use of batch or batch-like, even semibatch reactors would be more preferred than to work in CSTR, because-apart from the need of more complicated equipment and more amount of reagents - many of these ideas are not realizable if continuous flows are required. To meet the obvious need for closed system $\mathrm{pH}^{-}$ oscillators, two approaches have recently been suggested for designing batch or batch-like pH-oscillators: (i) Poros et al. replaced the mechanical inflow of $\mathrm{SO}_{3}{ }^{2-}$ by its dissolution from a layer of silica gel previously embedded with sodium sulfite. ${ }^{7}$ Such a gel in contact with the solution which contains the other components of the oscillatory system, can release sulfite ions at a relatively constant rate and, in such a way, it can induce $\mathrm{pH}$-oscillatory responses. (ii) Rábai applied sulfite salt of low solubility in water $\left(\mathrm{CaSO}_{3}, \mathrm{BaSO}_{3}, \mathrm{SrSO}_{3}\right)$ to supply continuously $\mathrm{SO}_{3}{ }^{2-}$ by dissolution and observed $\mathrm{pH}-$ oscillations in the heterogeneous $\mathrm{H}_{2} \mathrm{O}_{2}$ - solid sulfite- $\mathrm{HCO}_{3}{ }^{-}$ closed systems at very low temperature $\left(2-10^{\circ} \mathrm{C}\right) .{ }^{8}$ However, no oscillations in the mixture appeared when the $\mathrm{H}_{2} \mathrm{O}_{2}$ was replaced with $\mathrm{BrO}_{3}{ }^{-}$, instead, the concentration of $\mathrm{SO}_{3}{ }^{2-}$ released from the solid salt remained high, close to the value derived from the solubility product. The failure of seeing oscillations in the $\mathrm{BrO}_{3}{ }^{-}-\mathrm{CaSO}_{3}-\mathrm{HCO}_{3}{ }^{-}$closed system can be explained by the significant difference in the rate of the $\mathrm{BrO}_{3}{ }^{-}$ oxidation of the dissolved $\mathrm{SO}_{3}{ }^{2-}$ compared to the oxidation by $\mathrm{H}_{2} \mathrm{O}_{2}$. The $\mathrm{BrO}_{3}{ }^{-}$oxidation is sluggish, only a small fraction of $\mathrm{SO}_{3}{ }^{2-}$ is oxidised which amount is easily replenished by dissolution.

Our preliminary calculations indicated that the reaction between bromate and sulfite can exhibit long lasting oscillations not only in a CSTR but also under semibatch configuration and even in batch-like system of the type designed by Poros et al. Here, we report on new experimentally produced semibatch and batch-like $\mathrm{pH}$-oscillators consisting of only two components, $\mathrm{BrO}_{3}{ }^{-}$and $\mathrm{SO}_{3}{ }^{2-}$. First, the dynamical behavior in the reaction that takes place between bromate and sulfite under semibatch configuration is described, then the results where the inflow of sulfite solution into the reactor is replaced by dissolution of the sulfite from gel loaded with $\mathrm{Na}_{2} \mathrm{SO}_{3}$ will be discussed. Results of the model calculations are also presented.

\section{EXPERIMENTAL SECTION}

\section{A. Experiments in semibatch configuration}

Our semibatch reactor consisted of a cylindrical shaped water jacketed glass vessel equipped with a $\mathrm{pH}$ electrode, one inlet tube, and magnetic stirrer bar. The vessel was open to air. The initial volume of the liquid in the reactor was $100 \mathrm{~cm}^{3}$. A Haake thermostat was used to maintain a constant temperature of $\mathrm{T}=30{ }^{\circ} \mathrm{C}$ and $45^{\circ} \mathrm{C}$ in the reactor during the experiments. Stock solutions were prepared from reagent grade $\mathrm{KBrO}_{3}(0.1 \mathrm{M})$ and $\mathrm{Na}_{2} \mathrm{SO}_{3}$ $(1.0 \mathrm{M})$ without further purification. The stock solution of sulfite was made daily and kept from air to avoid air oxidation. Desired ratio of $\left[\mathrm{HSO}_{3}{ }^{-}\right] /\left[\mathrm{SO}_{3}{ }^{2-}\right]$ in the stock solution (see later) was adjusted by adding appropriate amount of sulfuric acid to the sulfite solution. The bromate solution was placed in the reactor at the start, and the sulfite-hydrogensulfite solution was flowed in by a peristaltic pump (Gilson) at measured rate. The reaction mixture was continuously stirred during the experiments at a rate of $500 \mathrm{rpm}$. The $\mathrm{pH}$ was measured with a Horiba $\mathrm{pH}$ meter and the $\mathrm{pH}$ vs time data were collected in every second and saved by personal computer.

\section{B. Experiments in gel-fed reactor}

In the experiments carried out under batch-like arrangement a beaker of volume $100 \mathrm{~cm}^{3}$ thermostatted to $\mathrm{T}=45.0^{\circ} \mathrm{C}$ served as reaction vessel. The gel layer loaded with high concentration of $\mathrm{Na}_{2} \mathrm{SO}_{3}$ was prepared in this reactor. A volume of $7.95 \mathrm{~cm}^{3}$ waterglass stock solution 
[prepared by mixing $30 \mathrm{~g}$ reagent grade $\mathrm{Na}_{2} \mathrm{SiO}_{3}$ solution (Sigma-Aldrich) with water in a $100 \mathrm{~cm}^{3}$ volumetric flask which contained $25.20 \mathrm{~g}(2.0 \mathrm{M}) \mathrm{Na}_{2} \mathrm{SO}_{3}$ ] was poured into the beaker then $3.00 \mathrm{~cm}^{3} 1.0 \mathrm{M} \mathrm{H}_{2} \mathrm{SO}_{4}$ was added to initiate gelation. The gel layer formed in the bottom of the vessel was about $7 \mathrm{~mm}$ thick, its surface area was $15.5 \mathrm{~cm}^{2}$ with a final $\left[\mathrm{Na}_{2} \mathrm{SO}_{3}\right]=1.45 \mathrm{M}$. In some experiments, the gel was prepared with using double volume of the reagents. The gel was rinsed with water before use. To look for oscillations $40-60 \mathrm{~cm}^{3}$ mixture of $\left[\mathrm{BrO}_{3}{ }^{-}\right]=0.10-0.15 \mathrm{M}$ and $\left[\mathrm{H}_{2} \mathrm{SO}_{4}\right]$ $=2.5 \times 10^{-3}-7.5 \times 10^{-3} \mathrm{M}$ was introduced above the gel layer and the changes in $\mathrm{pH}$ were followed in time. Care was taken to avoid the damage of the gel using gentle stirring (stirring rate of $100-250 \mathrm{rpm}$ ) with a propeller driven from the top of the reactor. The $\mathrm{pH}$ values measured in the reaction mixture in time were recorded as in the semibatch runs.

\section{THE MODEL}

To predict the dynamical behavior of the $\mathrm{BrO}_{3}{ }^{-}-\mathrm{SO}_{3}{ }^{2-}$ system under semibatch and batch conditions an empirical rate law model proposed by Szántó and Rábai was used. ${ }^{2}$ The composite reactions, rate equations, and corresponding rate laws established at $35.0^{\circ} \mathrm{C}$ were taken from Ref. 2 . The rate constant values for $45.0^{\circ} \mathrm{C}$ were estimated on the base of the average activation energies. The composite reactions and their empirical rate laws along with the rate constants are listed in Table I. Five species as variables $\left(\mathrm{BrO}_{3}{ }^{-}, \mathrm{SO}_{3}{ }^{2-}, \mathrm{HSO}_{3}{ }^{-}\right.$, $\mathrm{H}_{2} \mathrm{SO}_{3}, \mathrm{H}^{+}$) were taken into account in the differential equation system. The species $\mathrm{S}_{2} \mathrm{O}_{6}{ }^{2-}, \mathrm{SO}_{4}{ }^{2-}$, and $\mathrm{Br}^{-}$were not considered to be variables because they are end products and do not affect the rate of the composite reactions. The inflow of sulfite and that of hydrogen sulfite into the semibatch reactor was simulated with $\mathrm{k}_{0}\left[\mathrm{SO}_{3}{ }^{2-}\right]_{0}$ and $\mathrm{k}_{0}\left[\mathrm{HSO}_{3}{ }^{-}\right]_{0}$ terms, respectively, where $\mathrm{k}_{0}$ is the inflow rate in the reaction vessel $\left[\left(\mathrm{cm}^{3} / \mathrm{s}\right) /\right.$ average volume of reaction mixture $\left.\left(\mathrm{cm}^{3}\right)\right],\left[\mathrm{SO}_{3}{ }^{2-}\right]_{0}$ and $\left[\mathrm{HSO}_{3}^{-}\right]_{0}$ are the concentrations in the input stock solutions. For example, $\mathrm{k}_{0}=0.82 \mathrm{~cm}^{3} / 3600 \mathrm{~s} / 100 \mathrm{~cm}^{3}=2.3$ $\times 10^{-6} \mathrm{~s}^{-1}$ was used as typical value both in the experiments and simulations. For the simulations of the behavior in the gel-fed reactor, the input rate of $\left[\mathrm{SO}_{3}{ }^{2-}\right]$ was replaced by the dissolution rate of the sulfite which was determined experimentally. Since the dissolution rate varied in time, we used the following kinetics to simulate the experimentally measured $\left[\mathrm{SO}_{3}{ }^{2-}\right] v s$ time curve: $\mathrm{d}\left[\mathrm{SO}_{3}{ }^{2-}\right] / \mathrm{dt}=\mathrm{k}_{\mathrm{d}} \mathrm{t}^{-1 / 2}$. This type of rate law was introduced by Higuchi to describe the rate of release of suspended materials. ${ }^{9}$ The non-autonomous set of equations for modeling the batch systems has been solved by XPPAUT, with the cvode integrator (absolute tolerance $=10^{-12}$ and relative tolerance $\left.=10^{-5}\right) .{ }^{10}$

\section{RESULTS AND DISCUSSION}

\section{A. Results obtained in semibatch systems and simulations}

Preliminary model calculations showed that large amplitude $\mathrm{pH}$-oscillations are expected to appear if a mixture of sulfite and hydrogensulfite is introduced into a solution of bromate at a very low rate. According to these calculations, the ratio of input $\left[\mathrm{HSO}_{3}{ }^{-}\right]_{0} /\left[\mathrm{SO}_{3}{ }^{2-}\right]_{0}$ is an important parameter which determines the appearance of the oscillations in the bromate-sulfite reaction, therefore the effect of this ratio on the dynamical behavior was examined in detail.

In Figure 1, the measured and the calculated oscillatory regions are shown in the $\mathrm{k}_{0}$ vs $\left[\mathrm{HSO}_{3}{ }^{-}\right]_{0} /\left[\mathrm{SO}_{3}{ }^{2-}\right]_{0}$ phase plane. The agreement (overlapping) between the measured and calculated regions is fairly good. The calculated region of oscillations lies somewhat below the measured one. The experimentally determined lower and upper limits of the $\left[\mathrm{HSO}_{3}{ }^{-}\right]_{0} /\left[\mathrm{SO}_{3}{ }^{2-}\right]_{0}$ are $0.012-0.02$ and $0.04-0.06$, respectively, depending slightly on $\mathrm{k}_{0}$. From these calculations, we can conclude that a high excess of $\left[\mathrm{SO}_{3}{ }^{2-}\right]_{0}(94-99 \%)$ to the $\left[\mathrm{HSO}_{3}{ }^{-}\right]_{0}$ is necessary for giving rise to oscillations in a semibatch reactor. The $\mathrm{pH}$ of the input solution is a good indicator of the ratio of $\left[\mathrm{HSO}_{3}{ }^{-}\right]_{0} /\left[\mathrm{SO}_{3}{ }^{2-}\right]_{0}$. Derived from the $\mathrm{pK}$ value of reaction (1) in Table $\mathrm{I}$, the $\mathrm{pH}$ in the input mixture should be kept between 8.6 and 9.0 for the oscillations to occur.

The experiments in semibatch reactor were planned and carried out by taking into account the results of our preliminary simulations. The desired $\left[\mathrm{HSO}_{3}{ }^{-}\right]_{0} /\left[\mathrm{SO}_{3}{ }^{2-}\right]_{0}$ ratio was adjusted with addition of sulfuric acid to the input sodium sulfite solution. Typical oscillatory traces observed under semibatch conditions when the mixture of $\mathrm{Na}_{2} \mathrm{SO}_{3}$ and $\mathrm{H}_{2} \mathrm{SO}_{4}$ were pumped in a solution of $\mathrm{NaBrO}_{3}$ are shown in Figure 2. Part (a) of this figure depicts the semibatch $\mathrm{pH}$ oscillations measured at $\mathrm{T}=35.0^{\circ} \mathrm{C}$. These oscillations have been maintained for as long as $24 \mathrm{~h}$. During this long lasting experiments, the total volume in the reactor increased only by $19.5 \mathrm{~cm}^{3}$. The same experiment as shown in Part (a) of Figure 2 was carried out at $\mathrm{T}=45.0^{\circ} \mathrm{C}$ [Figure $1(\mathrm{~b})$ ]. At this elevated temperature, the oscillations last less (the system exhausted after $11 \mathrm{~h}$ ) and the period length is shorter. The temperature dependence of the period length can be characterized by a quotient of $\mathrm{Q}_{10}=2.1\left(\mathrm{Q}_{10}\right.$ is a measure of the change in the frequency of oscillations as a consequence of increasing the temperature by $10^{\circ} \mathrm{C}$ ).

The measured pH-oscillations shown in Figure 2 were simulated with the model in Table I. The calculated $\mathrm{pH}-$ oscillations are shown in Figure 3. Using the same ratio of

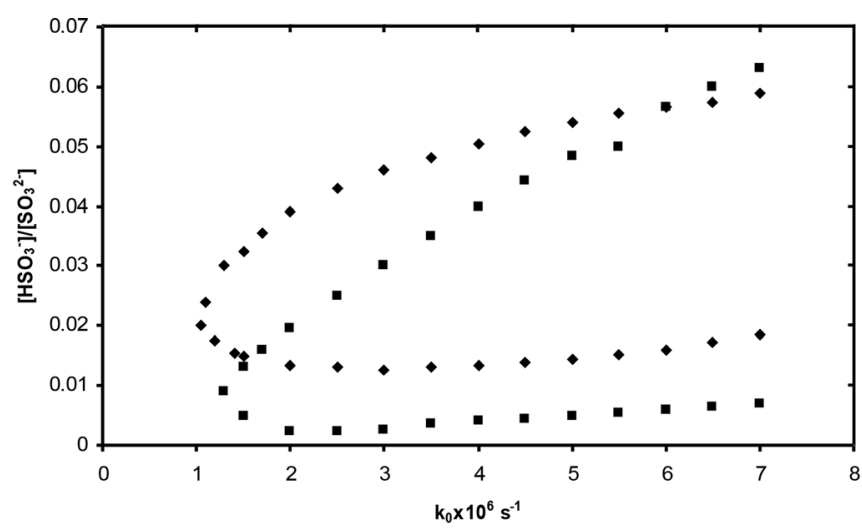

FIG. 1. Measured (bordered by the diamond-shaped points) and calculated (square points) regions of oscillations in the $\mathrm{k}_{0}$ vs $\left[\mathrm{HSO}_{3}{ }^{-}\right]_{0} /\left[\mathrm{SO}_{3}{ }^{2-}\right]_{0}$ phase plain. $\left[\mathrm{BrO}_{3}{ }^{-}\right]_{0}=0.10 \mathrm{M}, \mathrm{T}=35.0^{\circ} \mathrm{C}$. 
(a)

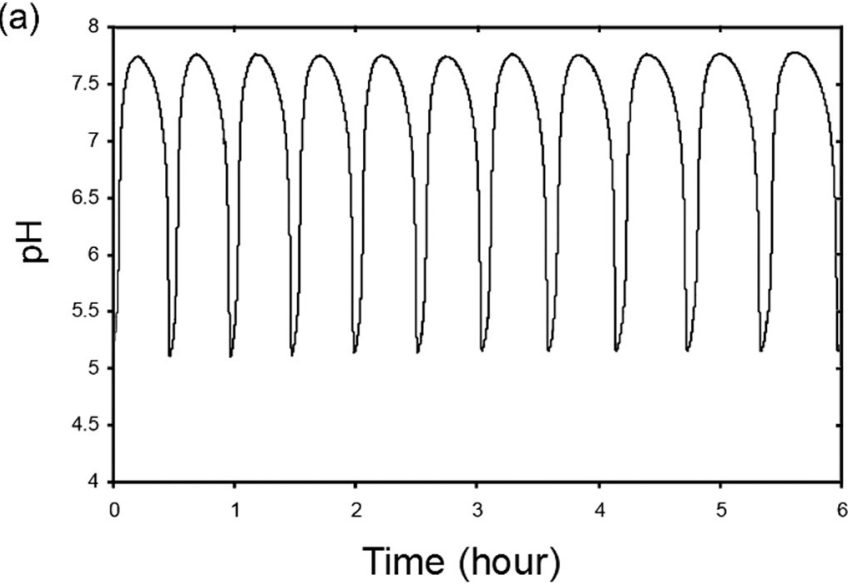

(b)

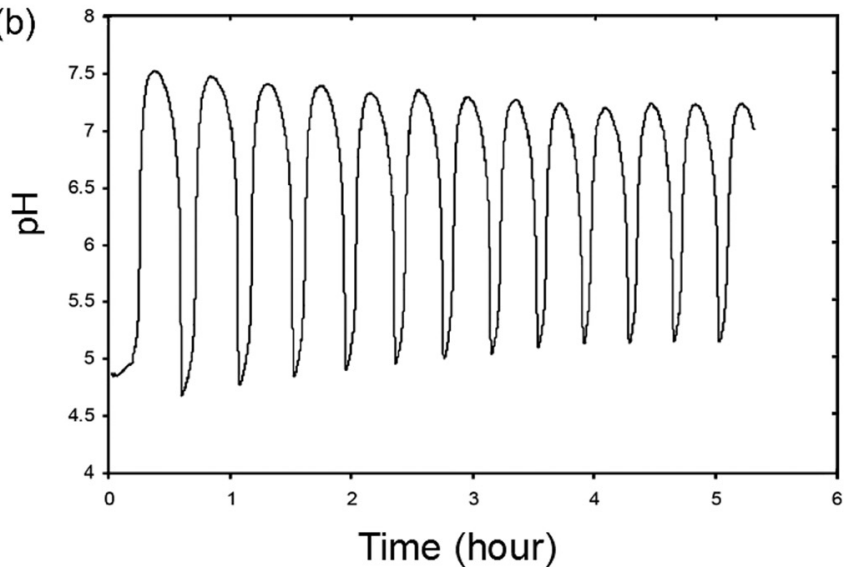

FIG. 2. The pH-oscillations in the $\mathrm{BrO}_{3}{ }^{-}-\mathrm{SO}_{3}{ }^{2-}$ reaction measured under semibatch configurations. Solution of $\left[\mathrm{Na}_{2} \mathrm{SO}_{3}\right]=1.0 \mathrm{M}$ containing $0.015 \mathrm{M}$ $\mathrm{H}_{2} \mathrm{SO}_{4}\left(\left[\mathrm{H}^{+}\right]_{0}=0.030 \mathrm{M}\right)$ was flowed into $100.0 \mathrm{~cm}^{3}$ of $0.10 \mathrm{M} \mathrm{NaBrO}_{3}$ at a rate of $0.81 \mathrm{~cm}^{3} / \mathrm{h}$. Part (a) $\mathrm{T}=35.0^{\circ} \mathrm{C}$, part (b) $\mathrm{T}=45.0^{\circ} \mathrm{C}$.

input $\left[\mathrm{H}^{+}\right]_{0} /\left[\mathrm{SO}_{3}{ }^{2-}\right]_{0}\left(\left[\mathrm{H}^{+}\right]_{0}=0.03 \mathrm{M}\right)$ as applied in the corresponding experiment, no oscillatory behavior could be calculated. However, choosing a little less hydrogen ion concentration $\left(\left[\mathrm{H}^{+}\right]_{0}=0.02 \mathrm{M}\right)$ in the calculations oscillatory traces very similar to those measured and shown in Figure 2 were simulated.

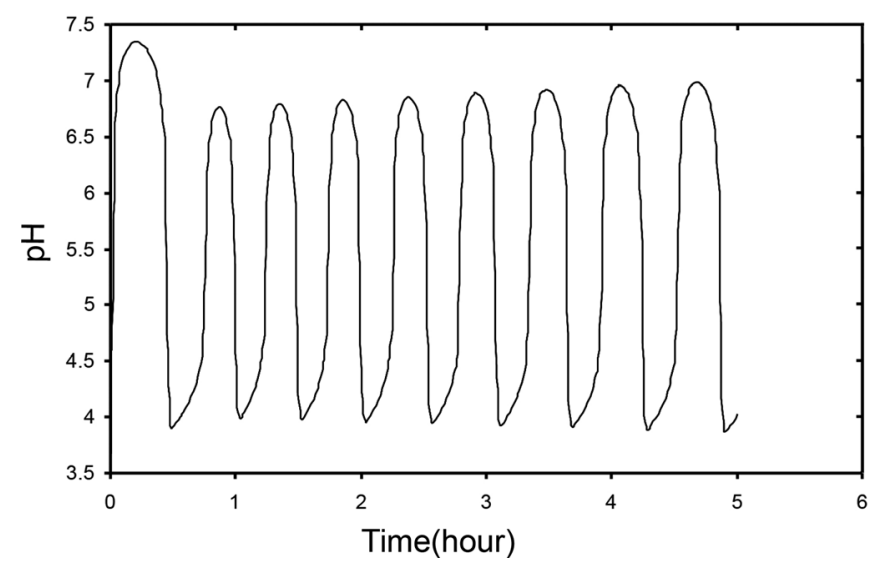

FIG. 3. Calculated pH-oscillations in semibatch reactor. Solution of $\left[\mathrm{Na}_{2} \mathrm{SO}_{3}\right]=1.0 \mathrm{M}$ containing $0.01 \mathrm{M} \mathrm{H}_{2} \mathrm{SO}_{4}\left(\left[\mathrm{H}^{+}\right]=0.02 \mathrm{M}\right)$ was used in the calculations. The input was simulated with $\mathrm{k}_{0}=2.28 \times 10^{-6} \mathrm{~s}^{-1}$ $\left(0.82 \mathrm{~cm}^{3} / 3600 \mathrm{~s} / 100 \mathrm{~cm}^{3}\right) \mathrm{T}=35.0^{\circ} \mathrm{C}$.

\section{B. Results obtained under closed system conditions and simulations}

The results obtained in the semibatch experiments and derived from the simulations were used as guide in our experiments aimed at converting the bromate-sulfite CSTR oscillator to function in a closed system. To reach this goal, instead of transporting the sulfite component into the reactor from outside by flow, the sulfite ions were generated inside the system in a way as it was suggested earlier and applied to produce $\mathrm{pH}$-oscillations under closed configuration in the $\mathrm{IO}_{3}{ }^{-}-\mathrm{SO}_{3}{ }^{2-}-\mathrm{Fe}(\mathrm{CN})_{6}{ }^{4-}, \quad \mathrm{BrO}_{3}{ }^{-}-\mathrm{SO}_{3}{ }^{2-}-\mathrm{Fe}(\mathrm{CN})_{6}{ }^{4-}, \quad$ and $\mathrm{BrO}_{3}{ }^{-}-\mathrm{SO}_{3}{ }^{2-}-\mathrm{Mn}(\mathrm{II})$ reactions. ${ }^{7}$ It was supposed that if the dissolution rate of the sulfite from the gel that was previously loaded with this reagent is comparable with the rate that was provided by the pump in the oscillatory semibatch experiments and if the ratio of the acid to sulfite in a solution above the gel falls in the range shown in Figure 1, then batch-like $\mathrm{pH}$-oscillations may appear in the $\mathrm{BrO}_{3}{ }^{-}-\mathrm{SO}_{3}{ }^{2-}$ system.

Dissolution experiments were carried out to establish the quantity of the sulfite that is released from the gel as function of time. The measurements were made under the conditions used in most of the batch-like oscillatory experiments (same gel size, gel thickness, surface area, volume of the solution above the gel, and temperature). $\mathrm{V}=60.0 \mathrm{~cm}^{3}$ water was repeatedly poured above the gel, after stirring for a definite time, the solution was decanted from the gel and the sulfite content was titrated with standard iodine solution. The quantity of the dissolved sulfite accumulated in the water above the sulfite-containing gel is plotted in time and shown in Figure 4. As it seems from the figure the dissolution process is long lasting, it becomes rather uniform after an hour before the gel is exhausted at 6-7 h. The experimentally measured $\left[\mathrm{SO}_{3}{ }^{2-}\right]$ vs time curve could be nicely simulated with using the kinetics of $\mathrm{d}\left[\mathrm{SO}_{3}{ }^{2-}\right] / \mathrm{dt}=\mathrm{k}_{6} \mathrm{t}^{-1 / 2}$, where $\mathrm{k}_{6}=2 \times 10^{-4} \mathrm{M} \mathrm{s}^{-1 / 2}$ incorporated as step 6 in the model of Table I.

Experiments were performed at the aim at finding oscillations in closed systems. Different volumes of mixtures of bromate stock solution and acid were poured above the sulfite-embedded silica gel. High amplitude $\mathrm{pH}$-oscillations were observed in the narrow range of the $\left[\mathrm{BrO}_{3}{ }^{-}\right]$and the

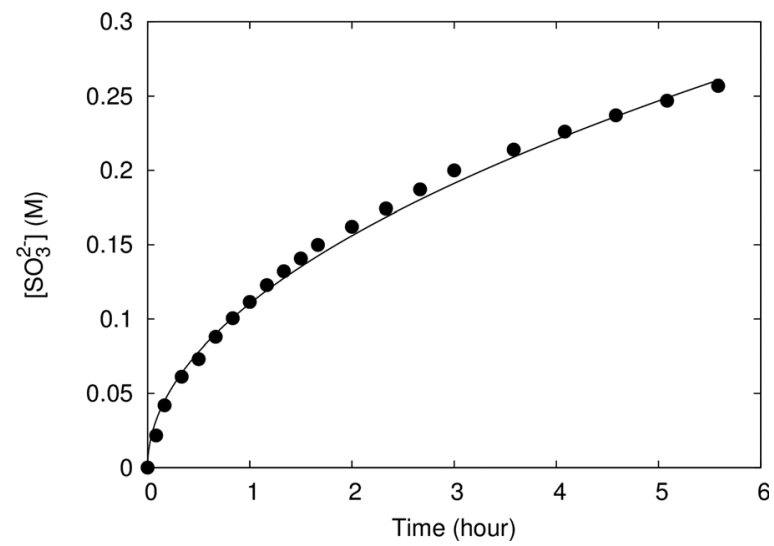

FIG. 4. Measured and simulated $\left[\mathrm{Na}_{2} \mathrm{SO}_{3}\right]$ released from the silica gel layer into distilled water above the gel. The dots $(\bullet)$ show the measured data, the solid line corresponds to the simulated curve. $\mathrm{T}=45.0^{\circ} \mathrm{C}$. 


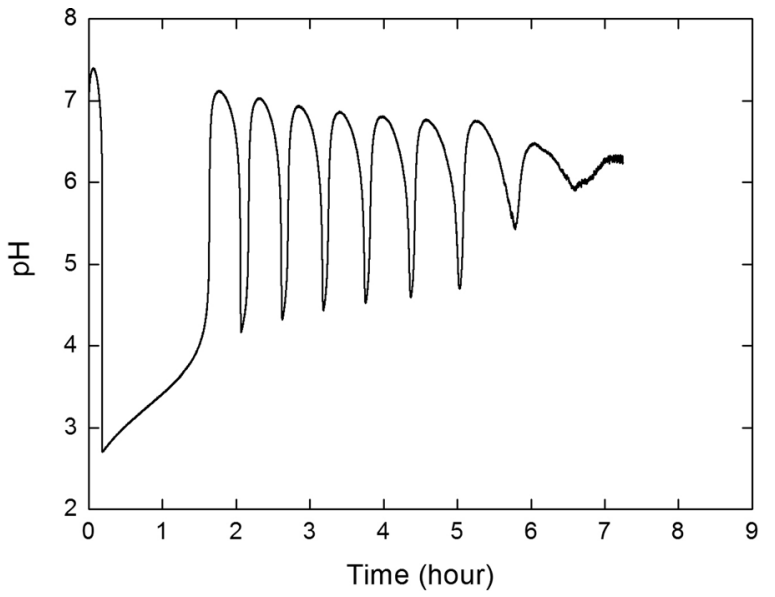

FIG. 5. Measured pH-oscillations in a gel-fed batch-like reactor. The oscillations were recorded in a $\mathrm{V}=60 \mathrm{~cm}^{3}$ mixture of $\left[\mathrm{BrO}_{3}{ }^{-}\right]=0.1 \mathrm{M}$ and $\left[\mathrm{H}^{+}\right]=0.0025 \mathrm{M}$ above the gel loaded with $\mathrm{Na}_{2} \mathrm{SO}_{3} . \mathrm{T}=45^{\circ} \mathrm{C}$.

initial $\left[\mathrm{H}^{+}\right]$. An oscillatory curve measured when a mixture of bromate and sulfuric acid was poured above the gel and the $\mathrm{pH}$ was recorded in time is shown in Figure 5.

A relative long induction period precedes the onset of the $\mathrm{pH}$-oscillations which last for about 5-6 h, but only 7-8 cycles with decreasing amplitude were obtained. We assume that ceasing the oscillatory behavior after about $6 \mathrm{~h}$ is due to the diminishing supply of sulfite from the gel. There is no way of preparation of a gel with higher sulfite content due to the limited solubility of $\mathrm{Na}_{2} \mathrm{SO}_{3}$ in the waterglass solution. The use of gel layers of larger surface area and wider thickness would probably lead to oscillatory patterns which show closer similarity to those observed in the semibatch experiments.

The $\mathrm{pH}$-oscillations measured in the gel-fed reactor were successfully simulated with the model in Table I supplemented with the Higuchi's kinetics. The oscillatory curve calculated under closed system arrangement is seen in Figure 6. The agreement between the measured and the calculated oscillatory parameters, the induction time, amplitude of $\mathrm{pH}-$ oscillations, the frequency, and the duration of the oscillations are reasonably good.

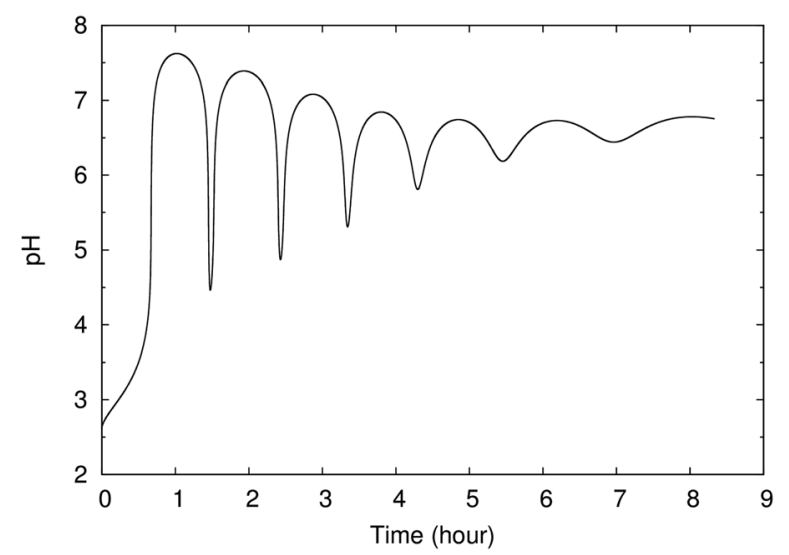

FIG. 6. The calculated pH-oscillations in the gel-fed reactor. The simulation was made by using the same conditions (concentrations and volume) as in Figure 5. The parameters as in Table $\mathrm{I}$ and $\mathrm{k}_{6}=2.3 \times 10^{-4} \mathrm{Ms}^{-1 / 2}$.

\section{CONCLUSIONS}

As it was mentioned in the Introduction in many present and potential applications of the $\mathrm{pH}$-oscillators the use of semibatch and closed configurations would be more preferred than that of the equivalent CSTR version, mainly because much less reagents and simpler experimental setup are required in the first case. Until now only CSTR pHoscillators have been linked to $\mathrm{pH}$-sensitive chemical and physical equilibra to induce periodic changes in the coupled systems. Among them the bromate-based oscillators proved to be best for providing the environment where the $\mathrm{pH}$ alternates. The bromate oscillators are well reproducible and sufficiently tolerant to the presence of the components of other systems. The $\mathrm{BrO}_{3}{ }^{-}-\mathrm{SO}_{3}{ }^{2-}, \mathrm{BrO}_{3}{ }^{-}-\mathrm{SO}_{3}{ }^{2-}-\mathrm{Fe}(\mathrm{CN})_{6}{ }^{4-}$ and $\mathrm{BrO}_{3}{ }^{-}-\mathrm{SO}_{3}{ }^{2-}-\mathrm{Mn}(\mathrm{II}) \mathrm{CSTR} \mathrm{pH}$-oscillators were applied to generate periodic pulses in the concentration of some nonredox ions $\left(\mathrm{Ca}^{2+}, \mathrm{Al}^{3+}, \mathrm{F}^{-}, \ldots\right),{ }^{11}$ to see oscillatory distribution of species in the $\mathrm{Ni}^{2+}$-histidine complex formation reaction $^{12}$ and in changes in the volume of hydrogels. ${ }^{13}$ These experiments could probably be carried out and the same information would be gained if semibatch or closed arrangements were used. When the $\mathrm{CSTR} \mathrm{BrO}_{3}{ }^{-}-\mathrm{SO}_{3}{ }^{2-}$ system is converted to a batch-like oscillator the main parameters of the oscillator hardly change. The amplitude of the $\mathrm{pH}$-oscillations remains large, the period time is similar, it runs for many hours: in semibatch system for a day, in closed one for 6-7 h. These features make them suitable to give rise to periodic changes not only in the fast chemical equilibria but also in the much slower $\mathrm{pH}$-sensitive physical processes, for example, if the repetitive movements in size of a $\mathrm{pH}$-dependent gel immersed in a solution where the $\mathrm{pH}$ oscillates, were subject to study. One of the goal in our ongoing research is to extend further the number of semibatch and closed $\mathrm{pH}$-oscillatory systems by testing those CSTR oscillators in which one of the components, either the oxidant or the reductant is in excess to the other constituents.

\section{ACKNOWLEDGMENTS}

This work was supported by grants from the Hungarian Academy of Sciences (OTKA K 100891) and by the EU, cofinanced by the European Social Fund under the project ENVIKUT (TAMOP-4.2.2.A-11/1/KONV-2012-0043).

${ }^{1}$ W. C. E. Higginson and J. W. Marshall, "Equivalence changes in oxidation-reduction reactions in solution: Some aspects of the oxidation of sulphurous acid," J. Chem. Soc. 447-458 (1957).

${ }^{2}$ T. G. Szántó and G. Rábai, "pH oscillations in the $\mathrm{BrO}_{3}{ }^{-}-\mathrm{SO}_{3}{ }^{2-} / \mathrm{HSO}_{3}{ }^{-}$ reaction in a CSTR," J. Phys. Chem. A 109, 5398-5402 (2005).

${ }^{3}$ E. C. Edblom, Y. Luo, M. Orbán, K. Kustin, and I. R. Epstein, "Kinetics and mechanism of the oscillatory bromate-sulfite-ferrocyanide reaction," J. Phys. Chem. 93, 2722-2727 (1989).

${ }^{4} \mathrm{G}$. Rábai and I. Hanazaki, "pH oscillations in the bromate-sulfite-marble semibatch and flow systems," J. Phys. Chem. 100, 10615-10619 (1996).

${ }^{5}$ N. Okazaki, G. Rábai, and I. Hanazaki, "Discovery of novel bromate-sulfite $\mathrm{pH}$-oscillators with $\mathrm{Mn}^{2+}$ or $\mathrm{MnO}_{4}^{-}$as a negative-feedback species," J. Phys. Chem. A 103, 10915-10920 (1999).

${ }^{6} \mathrm{~K}$. Chie, N. Okazaki, Y. Tanimoto, and I. Hanazaki, "Tristability in the bromate-sulfite-hydrogencarbonate pH oscillator," Chem. Phys. Lett. 334, 55-60 (2001). 
${ }^{7}$ E. Poros, V. Horváth, K. Kurin-Csörgei, I. R. Epstein, and M. Orbán, "Generation of pH-oscillations in closed chemical systems: method and applications," J. Am. Chem. Soc. 133, 7174-7179 (2011).

${ }^{8} \mathrm{G}$. Rábai, "pH-oscillations in a closed chemical system of $\mathrm{CaSO}_{3}-\mathrm{H}_{2} \mathrm{O}_{2}-\mathrm{HCO}_{3}{ }^{-}$," Phys. Chem. Chem. Phys. 13, 13604-13606 (2011).

${ }^{9} \mathrm{~T}$. Higuchi, "Rate of release of medicaments from ointment bases containing drugs in suspensions," J. Pharm. Sci. 50, 874-875 (1961).

${ }^{10}$ B. Ermentrout, Simulating, Analyzing, and Animating Dynamical Systems: A Guide to XPPAUT for Researchers and Students (SIAM, Philadelphia, PA, 2002).
${ }^{11}$ K. Kurin-Csörgei, I. R. Epstein, and M. Orbán, "Systematic design of chemical oscillators using complexation and precipitation equilibra," Nature 433, 139-141 (2005).

${ }^{12}$ E. Poros, K. Kurin-Csörgei, I. Szalai, V. Horvath, and M. Orbán, "Periodic changes in the distribution of species observed in the $\mathrm{Ni}^{2+}$ - histidine equilibrium coupled to the $\mathrm{BrO}_{3}{ }^{-}-\mathrm{SO}_{3}{ }^{2-} \mathrm{pH}$-oscillator," J. Phys. Chem. A 118, 6749-6756 (2014).

${ }^{13}$ C. Bilici, S. Karayel, T. T. Gemir, and O. Okay, "Self-oscillating pHresponsive cryogels as possible candidates of soft materials for generating mechanical energy," J. Appl. Polym. Sci. 118, 2981-2988 (2010). 